Article

\title{
Mutation Scanning in a Single and a Stacked Genetically Modified (GM) Event by Real-Time PCR and High Resolution Melting (HRM) Analysis
}

\author{
Sina-Elisabeth Ben Ali ${ }^{1,2, \dagger}$, Zita Erika Madi ${ }^{1, \dagger}$, Rupert Hochegger ${ }^{1}$, David Quist ${ }^{3}$, \\ Bernhard Prewein ${ }^{1}$, Alexander G. Haslberger ${ }^{2}$ and Christian Brandes ${ }^{1, *}$
}

1 Austrian Agency for Health and Food Safety, Spargelfeldstrasse 191, 1220 Vienna, Austria; E-Mails: sina-elisabeth.ben-ali@ages.at (S.-E.B.A.); zmadi@gmx.net (Z.E.M.); rupert.hochegger@ages.at (R.H.); bernhard.prewein@ages.at (B.P.)

2 Department of Nutritional Sciences, University of Vienna, Althanstraße 14, 1090 Vienna, Austria; E-Mail: alexander.haslberger@univie.ac.at

3 Centre for Biosafety-GenØk, PB 6418 Science Park, 9294 Tromsoe, Norway; E-Mail: david.quist@uit.no

$\dagger$ These authors contributed equally to this work.

* Author to whom correspondence should be addressed; E-Mail: christian.brandes@ages.at; Tel.: +43-5-0555-32202; Fax: +43-5-0555-32219.

External Editor: Virginia Garcia-Cañas

Received: 13 August 2014; in revised form: 11 October 2014 / Accepted: 21 October 2014 / Published: 31 October 2014

Abstract: Genetic mutations must be avoided during the production and use of seeds. In the European Union (EU), Directive 2001/18/EC requires any DNA construct introduced via transformation to be stable. Establishing genetic stability is critical for the approval of genetically modified organisms (GMOs). In this study, genetic stability of two GMOs was examined using high resolution melting (HRM) analysis and real-time polymerase chain reaction (PCR) employing Scorpion primers for amplification. The genetic variability of the transgenic insert and that of the flanking regions in a single oilseed rape variety (GT73) and a stacked maize (MON88017 × MON810) was studied. The GT73 and the 5' region of MON810 showed no instabilities in the examined regions. However; two out of 100 analyzed samples carried a heterozygous point mutation in the 3' region of MON810 in the stacked variety. These results were verified by direct sequencing of the amplified PCR products 
as well as by sequencing of cloned PCR fragments. The occurrence of the mutation suggests that the $5^{\prime}$ region is more suitable than the $3^{\prime}$ region for the quantification of MON810. The identification of the single nucleotide polymorphism (SNP) in a stacked event is in contrast to the results of earlier studies of the same MON810 region in a single event where no DNA polymorphism was found.

Keywords: HRM analysis; Scorpion primer; MON810; MON88017 × MON810; GT73; genetic stability; stacked event; GMO

\section{Introduction}

Since its introduction in 1996, the use of commercial genetically modified (GM) crops has drastically expanded. In the year 2013, 175.2 million hectares of GM crops were grown. Of these, less than 0.3 million hectares were cultivated in the EU (Spain, Portugal, Czech Republic, Romania, and Slovakia) to one singular maize variety (MON810) [1]. More recently, the commercialization of single events (for example MON810 maize or Roundup Ready Soy), have given way to the introduction of stacked events containing multiple transgenes [2]. Approximately 47 million hectares of stacked traits were grown in 2013, which is 3.3 million hectares more than that reported in 2012 [1]. There has been an increase in the number of approved stacked events and the number of transgenes stacked in a single plant (e.g., SmartStax ${ }^{\mathrm{TM}}$ maize, containing eight events) [2].

Authorization and compliance measures of GM food and feed require that GM events be genetically characterized and quantified. Additionally, transgene stability is important aspect to ensure food safety [3,4]. Reports on the genetic stability of genetically modified organisms (GMOs) have presented variable results. Initially, it was presumed that the production of transgenic plants involved the insertion of a single transgene and the flanking regions without further genomic disruption. However, instances of genomic alterations, including complex nucleotide rearrangements (e.g., deletions, duplications, insertions of organelle and filler DNA, and translocations) have occurred as a result of the transformation process [5-13]. The stability of the transgene, and gene expression as well as performance of the plant can be influenced by various factors, including host biology, genome organization, by epigenetic factors, or by nucleotide changes within the introduced DNA construct [4].

In addition to the requirement of genetic stability during GMO development, transgenic plants should demonstrate genetic stability subsequently during cultivation and propagation. Recent studies have identified the occurrence of DNA rearrangements after the transformation process and during the post-release monitoring. Choffnes et al. [14] studied transgene integration patterns of several hundred plants in subsequent generations. It was demonstrated that the original transgene integration patterns of regenerated primary transgenic plants $\left(\mathrm{T}_{0}\right)$ were not stable when passed to progenies, possibly due to a high level of homologous recombination. Another study performed cytogenetic analyses of GM maize and revealed a fragile phenotype of $45 \mathrm{~S}$ rDNA as a consequence of genetic modification [15]. McCabe et al. [11] detected differences in transgene expression between $\mathrm{T}_{0}$ plants and plants grown from selfed $\mathrm{T}_{0}$ seeds ( $\mathrm{T}_{1}$ generation) of transgenic lettuce. And it was suggested that these differences were due to inactivation or suppression of transgene expression. Ulian et al. [16] 
reported instabilities of transfer DNA (T-DNA) insertions in $\mathrm{T}_{0}$ plant genomes of petunia. Differences in plant protein expression that originated from different locations were also discovered $[17,18]$.

In recent years, new methods have been adapted for profiling the epigenome, proteome, and transcriptome of GMOs [19]. La Paz, et al. [20] analyzed cytosine methylation of the MON810 transgene in different MON810 varieties. The methylation level of the transgene was very low and a comparison between the different varieties revealed no significant differences in symmetric DNA methylation. In contrast, significant differences were observed in the asymmetric sites that play a minor role in epigenetics. Most of the reported comparative transcriptome analyses of MON810 maize were performed using microarrays [21-23]. La Paz et al. [24] analyzed MON810 and isogenic maize varieties using high-throughput RNA sequencing and found 140 differentially expressed genes. The authors suggested that the differences were due to a slightly delayed maturation process of MON810 compared to the conventional varieties. A proteomic approach was performed by Agapito-Tenfen et al. [25]. Using two-dimensional gel electrophoresis combined with mass spectrometry, 32 differentially expressed proteins were identified in Brazilian MON810 maize when compared to isogenic control maize. Rang et al. [26] detected different RNA variants transcribed from the transgene in Roundup Ready soybean which may code for 5-Enol-pyruvylshikimate-3-phosphate synthase (EPSPS) fusion proteins.

According to the European Food Safety Authority (EFSA) guidance document and the EU directive 2001/18/EC, the introduced DNA construct must be stable and no changes in the DNA construct should occur during the cultivation and propagation of the plants [27,28]. Even minor changes in the construct are critical because they may lead to unintended changes in the plant properties, content, and/or morphology [29]. Additionally, genetic heterogeneity in the samples may render the analysis for GMO detection unreliable or equivocal [30]. The EFSA guidance document details the requirements for the authorization of GMOs. Accordingly, the GMO events must be analyzed for DNA rearrangements and instabilities of the insert [27,28]. Genetic stability is commonly verified by Southern Blot analysis, however, Southern Blots have drawbacks, including low sensitivity (e.g., only major DNA changes can be detected). In many cases minor changes may occur, which can have an impact on the plant. A variety of methods have been used for analyzing minor nucleotide changes. Genomic samples can be sequenced directly or GMOs can be analyzed by methods such as Sensitive Capillary Electrophoresis (CSCE) or long-range polymerase chain reaction (PCR). Further, real-time PCR employing Scorpion primers for amplification or high resolution melting (HRM) analysis can be used to distinguish between different alleles or to filter out mutated samples [31,32].

According to EFSA, applicants must demonstrate the genetic stability of the transgenic locus over five generations or vegetative cycles before a product can be authorized. For stacked events, the applicant must establish the integrity of the inserts [33]. Further, EFSA determined that the risk assessment of stacked events consisting of events approved by the EU should focus on the genetic stability of such plants, the expression level of the transgenes, and unintended interactions between the stacked events [34]. The genetic stability of the single insert is verified by Southern Blot and segregation analyses before authorization [4,35,36]. The EU directive 2001/18/EC requires that the GMOs be inspected every 10 years [28]. Aguilera et al. recommended the validation of the genetic stability of inserts for the whole lifespan of a product [37].

In this study, the genetic stability of a stacked maize (MON88017 $\times$ MON810) and that of a single oilseed rape event (GT73) were investigated. MON88017 $\times$ MON810 is a maize variety produced 
by conventional crossing of a double-stacked maize (MON88017) that expresses a CP4 EPSPS gene from Agrobacterium sp. CP4, conferring resistance to glyphosate, and the coleopteran-active delta-endotoxin Cry3Bb1 gene from Bacillus thuringiensis $(\mathrm{Bt})$ ( $c r y 3 \mathrm{Bbl})$ to provide protection against coleopteran insects, particularly the maize rootworm, and the lepidopteran-active delta-endotoxin Cry1Ab (cry1Ab)-containing MON810 for protection against lepidopterans such as Ostrinia nubilalis and Sesamia spp. GT73 is a glyphosate-tolerant oilseed rape [38]. We used real-time PCR with Scorpion primers for amplification (Scorpion PCR) and HRM analysis to examine whether DNA alterations occurred amongst individual seeds (of MON88017 $\times$ MON810 maize) or plants (of GT73 oilseed rape). Earlier studies have adapted these methods to analyze the genetic stability and organization of transgenic insertion events. In Neumann et al. [32] it could be shown that single nucleotide polymorphism (SNPs) in plasmids can be demonstrated by Scorpion analysis. As a further work for optimizing the method, different alleles of the alcohol dehydrogenase $1(A D H 1)$ gene in maize were investigated by Madi et al. [31]. In single seeds, the homozygous as well as heterozygous state of the $A D H 1$ gene was found. Alleles can be discriminated using Scorpion PCR as well as by HRM analysis. They can be separated by cloning the PCR-amplified DNA. Testing of these clones allows a better differentiation between the alleles compared to testing only the genomic DNA.

In the present work, real-time PCR in combination with subsequent HRM analysis is used as a highly sensitive mutation scanning of selected DNA regions as a standardized means for determining the level of the genetic stability. Samples that potentially carried mutations were cloned into plasmids and sequenced by the Sanger method to verify the DNA alterations.

\section{Results and Discussion}

\subsection{Basics of Screening Genetically Modified Organisms (GMOs) for Genetic Stability Using} Scorpion Polymerase Chain Reaction (PCR) and High Resolution Melting (HRM) Analysis

We analyzed border regions between the endogenous plant genome and the exogenous transgene, known as "event-specific" regions. These regions are being used for the official GMO control. Unidentified mutations may render the test results unreliable. Therefore, we examined the border regions for establishing the genetic stability of GT73 in oilseed rape and MON810 in MON88017 × MON810 maize.

In contrast to the earlier investigations on MON810 [20,32], our study examined MON810 in a stacked event. Combinations of transgenic traits increase the complexity of risk assessment because more undesired scenarios may occur. At first the independent single events present in the stacked event should be safe and stable. In addition, interactions between the events as well as synergistic effects need to be analyzed [33]. Recent studies have demonstrated the suitability of real-time PCR with Scorpion primers and HRM analysis for investigating the nucleotide polymorphisms in genetically modified plants. These tests can be performed readily and are cost effective. The characterization of the Scorpion primers used for the analysis of GMOs has been described by Neumann et al. [32] and Thelwell et al. [39]. Madi et al. [31] have shown that Scorpion PCR combined with HRM analysis is a highly sensitive method for the detection of DNA alterations, including SNPs. Several studies have demonstrated the functionality of HRM analysis [40,41]. 
The potential genomic alterations were analyzed via a two- to three-step screening procedure, followed by sequencing. In the first step, a large number of individual seeds (MON88017 × MON810 maize samples) or leaves (GT73 oilseed rape samples) were tested using either real-time PCR with Scorpion primers or HRM analysis. The results of this step helped identify the samples that might harbor a genetic divergence. High $C_{\mathrm{t}}$ values obtained from Scorpion PCR analysis and low confidence values obtained from HRM analysis suggest a modification (SNP or other small sequence alterations) in the target region of the sample (see supplementary Figures S1-S4). Values from the first screening tests were used to select samples for a second round of screening with a lower number of genomic samples. Madi et al. have shown that PCR-cloning can be used to separate alleles from genomic samples containing heterozygous mutations [31]. Therefore, in the subsequent screening step, the same primers were used to clone the PCR fragments of the selected samples into plasmids. These plasmids were subjected to HRM analysis alone or HRM analysis and Scorpion PCR. The results from the last screening were used to filter out plasmids that harbor mutations. However, the HRM or Scorpion analysis of genomic samples or plasmids could yield false positive results due to variance among samples or because of variations in DNA quality. With the screening procedure alone, the number of true positive samples could not be determined. To avoid such artifacts and accurately identify samples that harbor alterations, the selected samples from the screening were subjected to sequencing as a secondary validation method.

\subsection{Screening of 5' Flanking Region of the GT73 (5'-GT73)}

The screening of the 5 ' junction of the oilseed rape variety was performed using a three-step procedure employing real-time PCR with Scorpion primers and HRM analysis. The analyzed target sequence of the 5'-GT73 region is shown in Figure 1. The primer sequences are marked in color and are additionally described in Table 1.

Figure 1. Illustration of the target sequence of the Scorpion primers and the High Resolution Melting (HRM) analysis employed for examining the 5 ' flanking region of the GT73 (5'-GT73) transgene. The forward primer is shown in red, and the blue letters indicate the reverse primer. The probe sequence (green) lies exactly along the transition from the transgene to the oilseed rape genome. The analyzed sequence contained 156 nucleotides.

\section{5'-CCAATCTGGAATGCTGCTAAATCCTGAGCTCAAGCTTGATGGGGATCAGATTGTCGTT TCCCGCCTTCAGTTTAAACTATCAGTGTTCGACTTTTTATGTAACAACCCGCCCCGGATC CAACCCCGAATCCCCGTATATTAATAGTTAAGGGGTCT-3’}

In total, 202 individual GT73 oilseed rape samples were tested by real-time PCR employing Scorpion primers and by HRM analysis on three different days. The $C_{\mathrm{t}}$ values ranged from 38.01 to 51.84 . The average $C_{\mathrm{t}}$ value and the standard deviation were $42.78 \pm 3.80$. A pool of 20 genomic GT73 oilseed rape samples (5'-GT73 pool) served as reference to calculate the confidence values. Further, the confidence values ranged from 0.67 to 99.67 , with an average value and a standard deviation of $55.44 \pm 29.44$. The distribution of the confidence values of the first screening was calculated according to Madi et al. [31]. Figure 2 shows the graphical distribution of the HRM measurements. 
Table 1. Sequences of primers used for real-time PCR screening and for PCR cloning.

\begin{tabular}{cc}
\hline Primer & Sequence \\
\hline 3 m810fw & 5'-CCAAGCACGAGACCGTCAA-3' \\
$3 \mathrm{~m} 810 \mathrm{rev}$ & 5'-GCTCGCAAGCAAATTCGGAA-3' \\
VW01 [41] & 5'-TCGAAGGACGAAGGACTCTAACG-3' \\
VW03 [41] & 5'-TCCATCTTTGGGACCACTGTCG-3' \\
5GT73fw & 5'-CCAATCTGGAATGCTGCTAAA-3' \\
5GT73rev & 5'-AGACCCCTTAACTATTAATATACGG-3' \\
5GT73Scorprev & 5'-[F]AAAAAGTCGAACACTGAT[Q][HEG]AGACCCCTTAACTATTAATATACGG-3' \\
3GT73fw & 5'-CCATATTGACCATCATACTCATTGCT-3' \\
3GT73rev & 5'-GCTTATACGAAGGCAAGAAAAGGA-3' \\
M13fw lo2 & 5'-AACGACGGCCAGTGAATTGTAATACG-3' \\
M13rev lo2 & 5'-CAGGAAACAGCTATGACCATGATTACG-3' \\
\hline
\end{tabular}

[F] Fluorophore, [Q] quencher, [HEG] stopper, the F/Q of 5GT73Scorprev are Cy5/BHQ1.

Figure 2. The distribution of the HRM measurements of 5'-GT73 oilseed rape tested by HRM analyses. For the HRM analysis, the confidence values (range: 0.67-99.67) were divided into 10 classes. The values of these classes are on the $x$-axis and the number of samples for the classes on the $y$-axis.

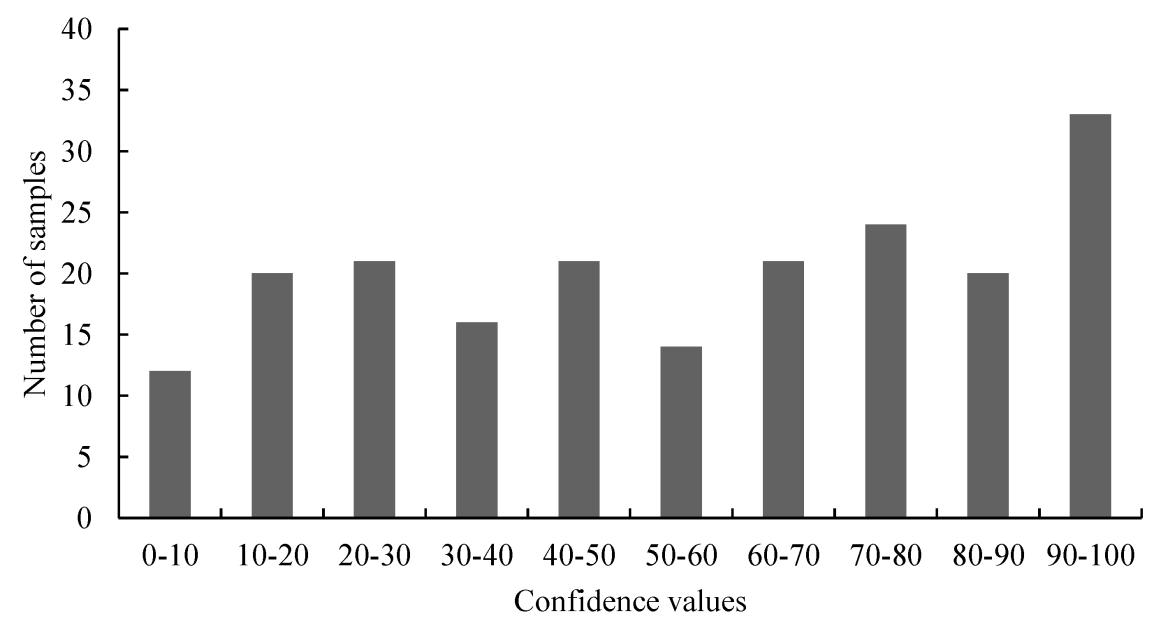

A total of 74 samples from the first round of screening showing high Scorpion $C_{\mathrm{t}}$ values or low confidence values were selected for further screening. In this screening step, confidence values of the HRM measurements and the $C_{\mathrm{t}}$ values of the Scorpion analysis were calculated. The $C_{\mathrm{t}}$ values varied between 37.69 and 46.44, with an average value and a standard deviation of $42.00 \pm 1.97$. For calculation of the confidence values the 5'-GT73 pool was used again. The confidence values ranged from 2.86 to 99.67. The average confidence value and the standard deviation were $62.29 \pm 30.12$. Based on the results of the first screening, eight samples with high $C_{\mathrm{t}}$ values and five samples with low confidence values as observed in the HRM analysis were selected for the second screening. Additionally, two control samples with average $C_{\mathrm{t}}$ and confidence values were determined. The data of the selected samples are presented in Table 2 (additional information of Table 2 is provided as supplementary file (Table $\mathrm{S} 1$ ). In the supplementary table, all $C_{\mathrm{t}}$ and confidence values of selected samples are presented). 
Table 2. (a) After the first screening, eight samples (13, 14, 18, 20, 30, 40, 152 and 170) were chosen for further analysis based on the $C_{\mathrm{t}}$ values. Sample 13 showed the highest $C_{\mathrm{t}}$ value; (b) Six samples $(137,152,153,156,157$ and 333) were selected because of low confidence values. Sample 152 was chosen because of high $C_{\mathrm{t}}$ and very low confidence values; (c) The two control samples, 118 and 175, with average $C_{\mathrm{t}}$ and confidence values are also shown.

\begin{tabular}{|c|c|c|c|c|c|c|c|c|c|}
\hline (a) & Sample & $C_{\mathrm{t}}$ Value & (b) & Sample & Confidence Value & (c) & Sample & $C_{\mathrm{t}}$ Value & Confidence Value \\
\hline & 13 & 51.84 & & 137 & 11.80 & & 118 & 40.54 & 35.13 \\
\hline & 14 & 47.64 & & 152 & 2.86 & & 175 & 41.40 & 37.49 \\
\hline & 18 & 48.30 & & 153 & 9.17 & & & & \\
\hline & 20 & 45.77 & & 156 & 9.11 & & & & \\
\hline & 30 & 45.93 & & 157 & 17.55 & & & & \\
\hline & 40 & 46.67 & & 333 & 10.15 & & & & \\
\hline & 152 & 46.57 & & & & & & & \\
\hline & 170 & 45.11 & & & & & & & \\
\hline
\end{tabular}

Based on the results of Madi et al., we assumed that nucleotide changes could also occur as heterozygous alleles [13]. Therefore, prior to the second screening, the selected samples were cloned into plasmids using PCR-cloning (see Experimental Section) to characterize the possible heterozygous alleles. From each selected sample (Table 2), two to three plasmids were generated and the DNA preparations were diluted to a concentration of $10^{-4} \mathrm{ng} / \mu \mathrm{L}$. These were tested in the second round of screening by real-time PCR employing Scorpion primers and were subsequently subjected to HRM analysis. A plasmid pool consisting of 20 plasmids served as reference. The results of the second screening are shown in Table 3.

Table 3. Illustration of the Scorpion $C_{\mathrm{t}}$ and HRM confidence values obtained from the second round of screening using plasmids.

\begin{tabular}{cccccc}
\hline Sample & $\boldsymbol{C}_{\mathbf{t}}$ Value & Confidence Value & Sample & $\boldsymbol{C}_{\mathbf{t}}$ Value & Confidence Value \\
\hline $13-2$ & 27.40 & 99.51 & $137-2$ & 29.12 & 94.98 \\
$13-3$ & 29.33 & 98.45 & $137-3$ & 30.67 & 99.02 \\
$14-1$ & 28.50 & 98.49 & $152-1$ & 38.42 & 90.38 \\
$14-3$ & 28.26 & 98.11 & $152-2$ & 29.33 & 99.04 \\
$18-1$ & 28.02 & 94.65 & $152-3$ & 28.36 & 86.10 \\
$18-2$ & 28.64 & 92.18 & $153-1$ & 29.30 & 99.18 \\
$20-1$ & 32.16 & 99.51 & $153-2$ & 28.07 & 93.83 \\
$20-2$ & 34.58 & 95.70 & $153-3$ & 29.19 & 96.05 \\
$20-4$ & 32.45 & 10.07 & $156-2$ & 29.92 & 88.81 \\
$30-2$ & 31.12 & 70.30 & $156-3$ & 27.35 & 97.89 \\
$30-3$ & 29.89 & 94.64 & $157-2$ & 33.44 & 81.05 \\
$30-5$ & 29.58 & 97.83 & $157-3$ & 27.74 & 98.92 \\
$40-1$ & 32.92 & 4.60 & $170-2$ & 31.27 & 95.93 \\
$40-2$ & 32.41 & 99.42 & $170-3$ & 31.36 & 25.01 \\
$40-3$ & 32.42 & 93.27 & $175-2$ & 31.44 & 16.65 \\
$118-1$ & 29.21 & 98.37 & $175-3$ & 28.48 & 0.00 \\
$118-2$ & 24.60 & 97.01 & $333-1$ & 28.52 & 93.82 \\
$118-3$ & 27.89 & 99.58 & $333-2$ & 38.83 & 78.62 \\
$137-1$ & 29.09 & 97.96 & & & \\
\hline
\end{tabular}


Because plasmids with low confidence values $(<50)$ could possibly contain SNPs, samples 20-4, 40-1, 170-3, 175-2, and 175-3 were selected for sequencing. Sequencing results showed no genetic instabilities. To exclude the possibility that the low number of plasmids generated per genomic sample prevented the identification of heterozygous DNA samples, we generated 30 more plasmids from the genomic samples 40, 175 and 333 (10 plasmids per sample). These plasmids were tested by Scorpion PCR and HRM analyses. The above-mentioned plasmid pool served as reference again. Results of this screening are depicted in Table 4.

As shown in Table 4, the $C_{\mathrm{t}}$ values ranged from 20.69 to 23.44 and the confidence values ranged from 69.21 to 99.79 . With both, $C_{\mathrm{t}}$ values and confidence values, the differences between samples were very low. Nevertheless, a minimum of one plasmid per group was sequenced. However, differences in the nucleotide sequence were not detected. Thus, real-time PCR and HRM analyses revealed no genetic instabilities in the analyzed 5' flanking region of the GT73 oilseed rape.

Table 4. Scorpion $C_{\mathrm{t}}$ and HRM confidence values obtained from the screening of additional plasmids (containing 5'-GT73 region). For each genomic sample, 10 cloned fragments were obtained (differentiated by letters a to $\mathrm{k}$ ).

\begin{tabular}{cccccc}
\hline Sample & $\boldsymbol{C}_{\mathbf{t}}$ Value & Confidence Value & Sample & $\boldsymbol{C}_{\mathbf{t}}$ Value & Confidence Value \\
\hline $40-\mathrm{a}$ & 23.44 & 99.64 & $175-\mathrm{f}$ & 21.25 & 97.37 \\
$40-\mathrm{b}$ & 22.08 & 97.46 & $175-\mathrm{g}$ & 22.31 & 84.30 \\
$40-\mathrm{c}$ & 22.25 & 95.40 & $175-\mathrm{h}$ & 21.16 & 90.70 \\
$40-\mathrm{d}$ & 22.78 & 98.56 & $175-\mathrm{i}$ & 21.08 & 98.68 \\
$40-\mathrm{e}$ & 22.32 & 96.64 & $175-\mathrm{k}$ & 23.05 & 98.79 \\
$40-\mathrm{f}$ & 21.99 & 97.56 & $333-\mathrm{a}$ & 22.25 & 99.79 \\
$40-\mathrm{g}$ & 22.40 & 99.00 & $333-\mathrm{b}$ & 22.15 & 97.95 \\
$40-\mathrm{h}$ & 22.10 & 98.95 & $333-\mathrm{c}$ & 22.30 & 96.00 \\
$40-\mathrm{i}$ & 22.14 & 95.38 & $333-\mathrm{d}$ & 21.77 & 91.31 \\
$40-\mathrm{k}$ & 22.19 & 97.35 & $333-\mathrm{e}$ & 21.72 & 71.89 \\
$175-\mathrm{a}$ & 21.09 & 99.26 & $333-\mathrm{f}$ & 22.27 & 85.75 \\
$175-\mathrm{b}$ & 21.02 & 96.66 & $333-\mathrm{g}$ & 21.88 & 85.34 \\
$175-\mathrm{c}$ & 23.38 & 98.21 & $333-\mathrm{h}$ & 21.60 & 85.15 \\
$175-\mathrm{d}$ & 22.05 & 93.81 & $333-\mathrm{i}$ & 21.70 & 99.57 \\
$175-\mathrm{e}$ & 21.30 & 97.86 & $333-\mathrm{k}$ & 20.69 & 69.21 \\
\hline
\end{tabular}

\subsection{Screening of 3' Flanking Region of the GT73 (3'-GT73)}

Although we attempted to use Scorpion PCR followed by HRM analysis to screen the 3' flanking region of the GT73 transgene for mutations, we were unable to develop an adequate Scorpion primer with the desired elements. Specifically, we were unable to distinguish a wild-type plasmid from a plasmid with a 2-bp deletion. Therefore, the first screening was performed using HRM analysis alone. A 108-bp nucleotide sequence at the 3'-GT73 flanking region was analyzed using real-time PCR and HRM analyses. Figure 3 shows the 3'-GT73 target sequence. The primer sequences are presented in Table 1. 
Figure 3. Illustration of the target sequence used in the HRM analysis of the 3 ' junction of GT73 transgene. The transgene sequence is at the $3^{\prime}$ region, and the transition to the genome lies in the underlined region. The forward primer is shown in red and the blue letters indicate the reverse primer. The sequence contains 108 nucleotides.

\section{5 -CCATATTGACCATCATACTCATTGCTGATCCATGTAGATTTCCCGGACATGAAGATC ATCCTCCTTCCTTTCCTTGCCTTTCCTTCCTTTTCTTGCCTTCGTATAAGC-3'}

All in all, 510 individual samples were screened by HRM analysis. The average confidence value and the standard deviation were $55.16 \pm 33.60$. A pool of 20 genomic GT73 oilseed rape samples (3'-GT73 pool) served as reference to calculate the confidence values. The distribution of the confidence values was also calculated. The confidence values of the screening were divided into 10 groups and the cluster frequencies were determined.

As illustrated in Figure 4, the clusters with the lowest and the highest confidence values had the highest frequencies. The distribution of the 3'-GT73 confidence values was congruent to a bimodal sample pool containing wild-type (confidence values $>90$ ) and mutant (confidence values $<10$ ) samples. For further investigations, 47 samples with low confidence values were selected and screened two times using HRM analysis. The genomic 3'-GT73 pool served as reference. Based on the average values of this screening, 10 samples with the lowest confidence values were selected (Table 5).

Figure 4. The distribution of the HRM measurements of 3'-GT73 oilseed rape. For the HRM analysis, the confidence values (range: 0.00-99.97) were divided into 10 classes. The values of these classes were drawn on the $x$-axis and the number of samples for the classes on the $y$-axis.

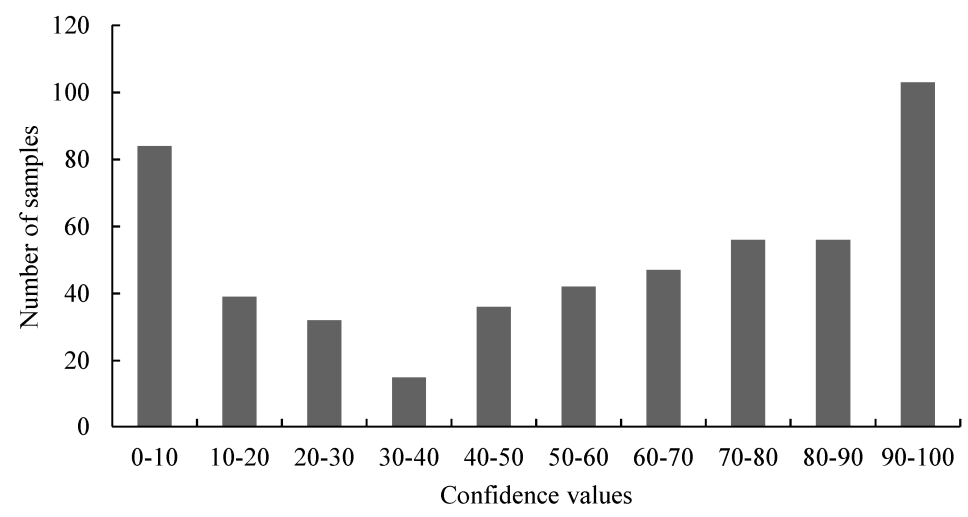

Table 5. The samples 50, 51, 63, 70, 72, 99, 145, 379, 388 and 494 were chosen based on the confidence values of the second screening. Sample 63 had the lowest confidence value.

\begin{tabular}{cc}
\hline Sample & Confidence Value \\
\hline 50 & 1.31 \\
51 & 1.69 \\
63 & 0.94 \\
70 & 4.14 \\
72 & 1.00 \\
99 & 3.16 \\
\hline
\end{tabular}


Table 5. Cont.

\begin{tabular}{cc}
\hline Sample & Confidence Value \\
\hline 145 & 10.44 \\
379 & 10.05 \\
388 & 25.31 \\
494 & 55.22 \\
\hline
\end{tabular}

These genomic samples were cloned into plasmids by PCR-cloning (Zero Blunt TOPO PCR Cloning kit). For the PCR, a high-fidelity proofreading enzyme (Phusion Hot Start II DNA Polymerase) was used and the same primer pair employed for the first 3'-GT73 screening was utilized. One or two plasmids were generated per selected genomic sample. Plasmid preparations were diluted to a concentration of $10^{-4} \mathrm{ng} / \mu \mathrm{L}$ and analyzed in a second screening step using the 3'-GT73 primer pair. A pool of 10 plasmids served as reference. The results of the second screening are shown in Table 6.

Table 6. In the second screening, 17 plasmids were analyzed. The confidence values ranged from 86.96 to 99.92 .

\begin{tabular}{cc}
\hline Sample & Confidence Value \\
\hline $50-3$ & 92.04 \\
$50-4$ & 99.92 \\
$51-1$ & 95.27 \\
$51-2$ & 97.84 \\
$63-1$ & 86.96 \\
$70-1$ & 96.85 \\
$72-1$ & 89.00 \\
$72-2$ & 99.54 \\
$99-2$ & 98.34 \\
$99-3$ & 98.83 \\
$145-1$ & 94.89 \\
$145-2$ & 98.18 \\
$379-3$ & 96.40 \\
$379-4$ & 99.78 \\
$388-1$ & 99.67 \\
$494-1$ & 99.81 \\
$494-2$ & 99.78 \\
\hline
\end{tabular}

The confidence values obtained for the plasmids in the second screening are different from those of the first screening with genomic samples. Whereas the confidence values of the selected samples in the first HRM screening were low (eight samples below 11 and two samples below 60; Table 5), the HRM analysis of the second screening yielded very high confidence values $(>85)$. Based on these results, we concluded that none of the samples had a mutation in the targeted region. To verify this, two plasmids were sequenced. Sequencing confirmed that mutations were absent. Thus, the analysis of the 3' flanking region of the GT73 transgene in oilseed rape leaves revealed no genetic instabilities. 


\subsection{Screening of 5' Junction of MON810 (5'-MON810)}

For the investigation of $5^{\prime}$ junction of MON810 (5'-MON810), a stacked GM maize variety $($ MON88017 $\times$ MON810) containing three genetic elements was used. The analyzed target region has been described by Neumann et al. [32] and the primers are shown in Table 1. It was possible to test this region using Scorpion PCR [32] and HRM analysis. However, because Scorpion analysis only reveals DNA alterations in the probe and primer regions and HRM analysis identifies changes in the whole target sequence, only HRM analysis was performed. For the screening of the 5'-MON810 region, a two-step procedure was employed. In the first step, individual genomic samples of seeds were tested using real-time PCR and HRM analyses. In the second step, the genomic samples that showed the possible presence of mutations were cloned into plasmids and examined by HRM analysis. Finally, these plasmids were sequenced to identify possible mutations. Figure 5 gives an overview of the screening schema.

Figure 5. The two-step screening schema for the analysis of MON810. Only samples with low confidence values in the first screening were selected for the second screening. Samples with high confidence values were associated with wild-type and were not analyzed. Approximately six or more plasmids were generated per selected genomic sample. After the final screening step, selected plasmids were sequenced to identify DNA alterations, and the type and the exact location of the mutations were determined.

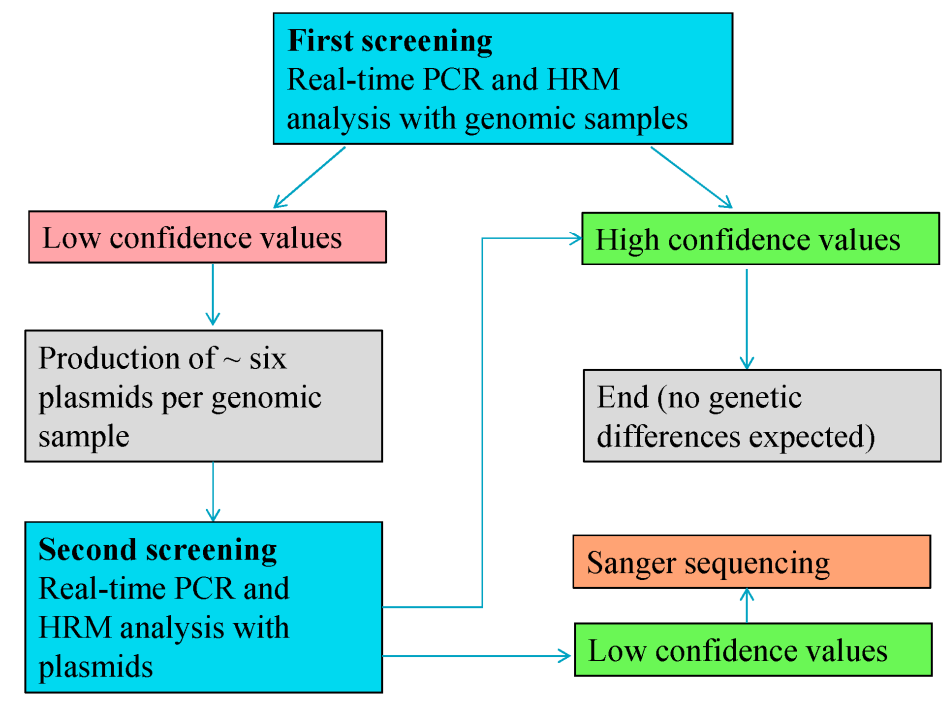

In the first step, 50 maize samples $(\mathrm{MON} 88017 \times$ MON810) were tested twice (separately on different days). A pool of 20 genomic maize samples (MON88017 $\times$ MON810) served as reference to calculate the confidence values. Figure 6 shows the graphical distribution of the HRM measurements. If the samples harbored mutations, a distribution similar to that in Figure 4 would be expected and very high (wild-type) and very low (mutants) confidence values would be very frequent. However, this was not observed. Cluster 10 showed the highest frequency, whereas cluster one had a very low frequency. The confidence values ranged from 13.16 to 99.83 . The average confidence value and the standard deviation were $77.88 \pm 23.36$. 
Figure 6. The distribution of the HRM measurements of the $5^{\prime}$ junction of MON810 (5'-MON810) region tested with real-time PCR. For the HRM analysis the confidence values were divided into 10 classes. The values of these classes were plotted on the $x$-axis and the numbers of the samples for the classes on the $y$-axis.

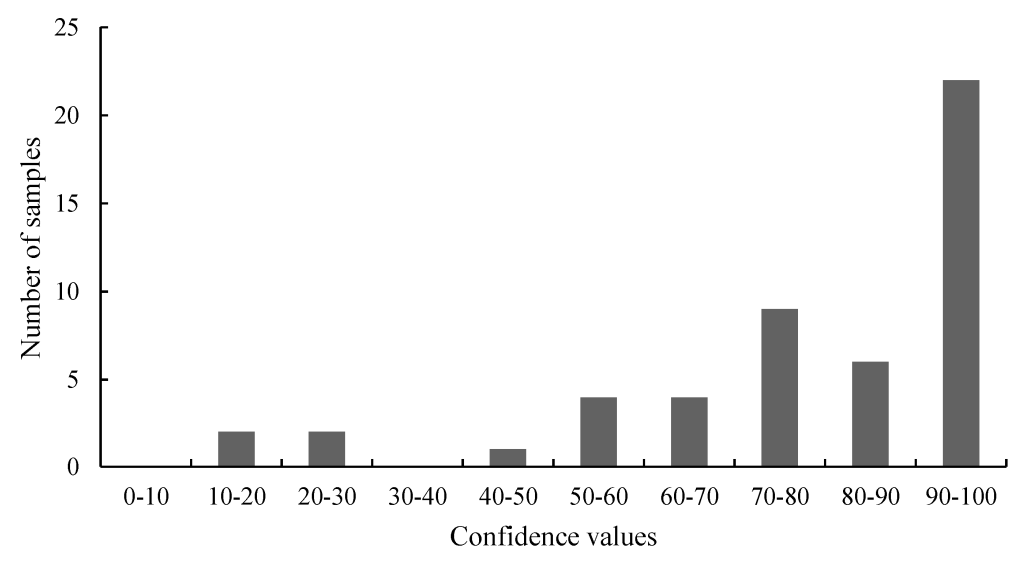

Samples with confidence values below 10 were not present. Four samples, which had confidence values below 25, were chosen for the second screening. Additionally, sample 383 was selected because a pre-screening revealed that this sample contained an SNP in the coding region of the MON810 transgene (see Section 2.5.). The selected samples and the confidence values of the first 5'-MON810 screening are shown in Table 7.

Table 7. Four samples, 272, 275, 322 and 354 were chosen based on the confidence values of the first screening. Sample 383 was selected because it showed a DNA alteration at the 3'-MON810 junction.

\begin{tabular}{cc}
\hline Sample & Confidence Value \\
\hline 272 & 22.41 \\
275 & 23.18 \\
322 & 15.95 \\
354 & 13.16 \\
383 & 75.80 \\
\hline
\end{tabular}

The 5'-MON810 target region of the chosen maize samples was cloned into plasmids by PCR-cloning (see Experimental Section). Results from our analysis of GT73 suggested that a high number of clones are necessary to distinguish the authentic mutations from artifacts. Therefore, six plasmids with cloned PCR fragments were obtained for each sample. Thus, a total 30 plasmids were obtained and tested in the second 5'-MON810 screening round using HRM analysis employing the same primer pair as that used for the first screening. The confidence values ranged from 17.88 to 99.94 . The average value and the standard deviation were $95.02 \pm 15.15$. Table 8 shows the confidence values of the second screening. 
Table 8. Plasmid 272-5 served as reference (confidence value of 100). Plasmids 275-8 and 272-4 showed the lowest confidence values.

\begin{tabular}{cccc}
\hline Plasmid & Confidence Value & Plasmid & Confidence Value \\
\hline $272-2$ & 99.66 & $322-4$ & 90.11 \\
$272-3$ & 99.94 & $322-5$ & 96.53 \\
$272-4$ & 79.48 & $322-6$ & 99.14 \\
$272-5$ & 100.00 & $354-1$ & 99.75 \\
$272-6$ & 99.62 & $354-2$ & 99.17 \\
$272-8$ & 99.23 & $354-4$ & 91.91 \\
$275-1$ & 96.43 & $354-5$ & 99.56 \\
$275-2$ & 95.71 & $354-7$ & 99.55 \\
$275-3$ & 98.19 & $354-8$ & 99.62 \\
$275-5$ & 98.91 & $383-2$ & 97.87 \\
$275-6$ & 99.68 & $383-3$ & 96.63 \\
$275-8$ & 17.88 & $383-4$ & 98.40 \\
$322-1$ & 99.88 & $383-5$ & 99.63 \\
$322-2$ & 98.81 & $383-6$ & 99.67 \\
$322-3$ & 99.71 & $383-7$ & 99.92 \\
\hline
\end{tabular}

As shown in Table 8, only plasmid 275-8 had a low confidence value (17.88). Plasmid 272-4 showed the second lowest value (79.48). All other plasmids showed a confidence value of $>90$ and therefore were associated with the wild-type. To verify if the plasmids 275-8 and 272-4 harbored mutations, these samples were subjected to Sanger sequencing. The sequencing revealed an SNP, a $\mathrm{C} \rightarrow \mathrm{T}$ substitution, at position 147 in plasmid 275-8, but not in 272-4. Because no other plasmid generated from the sample 275 showed this DNA alteration, this SNP was assessed as due to polymerase error. Polymerase errors can occur even when high-fidelity enzymes are used. The theoretical probability of having a polymerase error in the present cloning sequence was 0.003 (calculated according to Foissac) [42]. Thus, three out of 1000 fragments may contain an error. The calculated error frequency is markedly lower than that expected based on the results of our experiments. A somatic mutation can also be the reason for the altered DNA sequence of sample 275-8. However, false positive results demonstrate the importance of the cloning step and the subsequent detailed characterization of these plasmids after the first screening.

\subsection{Screening of 3' Junction of MON810 (3'-MON810)}

We analyzed the 3' junction of MON810 (3'-MON810) region of the GMO variety MON88017 $\times$ MON810. The 3'-MON810 target sequence has been reported previously by Neumann et al. [32]. The primers are shown in Table 1. The two-step procedure shown in Figure 5 was used for screening. The distribution of the HRM measurements is shown in Figure 7. Based on this distribution, no or very few mutations would be expected. This is because a bimodal distribution was not evident. A pool of 20 genomic maize samples (MON88017 $\times$ MON810) served as reference to calculate the confidence values. The confidence values ranged from 0.54 to 99.03 . The average confidence value and the standard deviation were $57.91 \pm 29.59$. 
Figure 7. The distribution of the HRM measurements of the $3^{\prime}$ junction of MON810 (3'-MON810) region tested with real-time PCR. For the HRM analysis the confidence values were divided into 10 classes. The values of these classes were plotted against the number of samples.

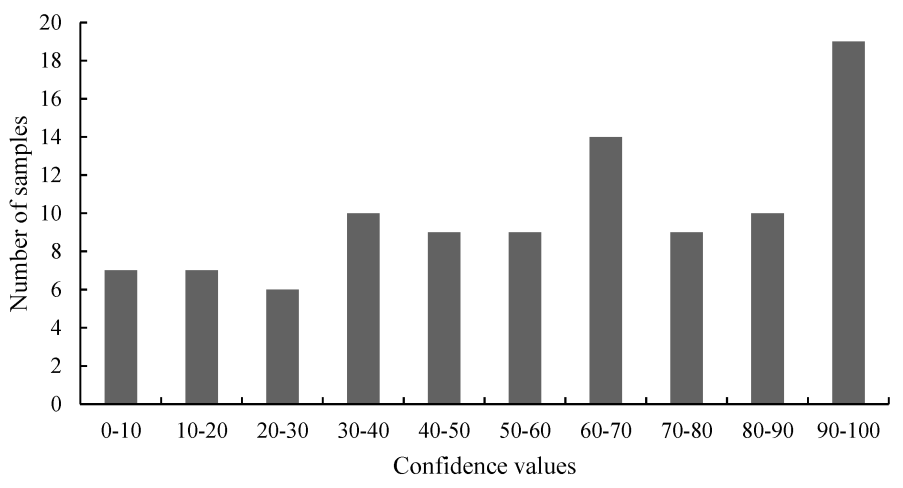

For the second screening, eight samples from clusters one and two were chosen. Table 9 shows the selected samples and the confidence values obtained from the HRM analysis performed for the first screening.

Table 9. The eight samples shown were selected for the second screening because they resulted in low confidence values in the first screening.

\begin{tabular}{cc}
\hline Sample & Confidence Value \\
\hline 263 & 10.95 \\
264 & 1.23 \\
345 & 0.54 \\
352 & 7.91 \\
354 & 8.45 \\
355 & 3.01 \\
374 & 10.88 \\
383 & 4.81 \\
\hline
\end{tabular}

The 3'-MON810 target regions of the chosen maize samples were cloned into plasmids (see Experimental Section). For each sample, six plasmids were obtained and are shown in Table 9. Thus, in the second 3'-MON810 screening, 48 plasmids were subjected to HRM analysis using the same primer pair as that employed for the first screening. The confidence values ranged from 2.94 to 99.14. The average value and the standard deviation were $70.46 \pm 33.69$. Table 10 shows the confidence values obtained from the second screening.

Table 10. A total of 48 plasmids (containing the 3'-MON810 target region) were analyzed in the second screening. The plasmid 383-2 served as reference (confidence value of 100).

\begin{tabular}{cccc}
\hline Plasmid & Confidence Value & Plasmid & Confidence Value \\
\hline $263-2$ & 67.69 & $354-1$ & 44.77 \\
$263-3$ & 72.02 & $354-2$ & 15.97 \\
$263-4$ & 66.57 & $354-3$ & 90.48 \\
$263-5$ & 62.97 & $354-4$ & 64.39 \\
\hline
\end{tabular}


Table 10. Cont.

\begin{tabular}{cccc}
\hline Plasmid & Confidence Value & Plasmid & Confidence Value \\
\hline $263-7$ & 82.78 & $354-5$ & 62.92 \\
$263-8$ & 88.24 & $354-6$ & 81.43 \\
$264-1$ & 88.51 & $355-1$ & 91.75 \\
$264-2$ & 7.99 & $355-2$ & 90.81 \\
$264-3$ & 4.61 & $355-3$ & 89.48 \\
$264-4$ & 4.95 & $355-4$ & 95.72 \\
$264-6$ & 6.01 & $355-5$ & 94.10 \\
$264-7$ & 7.97 & $355-7$ & 94.76 \\
$345-2$ & 64.71 & $374-2$ & 99.14 \\
$345-3$ & 75.71 & $374-3$ & 99.01 \\
$345-4$ & 78.59 & $374-4$ & 98.39 \\
$345-5$ & 86.28 & $374-6$ & 98.75 \\
$345-6$ & 91.02 & $374-7$ & 98.61 \\
$345-7$ & 84.85 & $374-8$ & 96.73 \\
$352-1$ & 81.06 & $383-1$ & 3.14 \\
$352-2$ & 96.06 & $383-2$ & 100.00 \\
$352-3$ & 95.95 & $383-5$ & 97.56 \\
$352-4$ & 97.95 & $383-7$ & 95.53 \\
$352-5$ & 93.88 & $383-8$ & 6.40 \\
$352-6$ & 92.63 & $383-9$ & 2.9 \\
\hline
\end{tabular}

Several plasmids were chosen for sequencing. These are depicted in Table 11. Altered nucleotide sequences were detected in 14 plasmids. These changes were verified by forward and reverse sequencing. The plasmids with altered nucleotide sequences belonged to three different genomic samples, 264, 354 and 383. In the case of sample 264, six out of seven plasmids showed a $\mathrm{C} \rightarrow \mathrm{T}$ substitution at position 71 of the analyzed 3'-MON810 target sequence, whereas four of seven plasmids of sample 383 showed a $\mathrm{C} \rightarrow \mathrm{T}$ substitution at position 71. A heterozygous SNP appeared to be present in sample 383. For sample 264 it was not clear whether the SNP was homozygous or heterozygous. Thus, the PCR product of the 3'-MON810 target region in sample 264 was subjected to direct sequencing. As shown in Figure 8, the result indicated that the SNP was heterozygous. In the sequencing chromatogram, an overlay of two peaks was present at position 71. A thymine peak was found to overlay a cytosine peak. Direct sequencing of the 3'-MON810 target region of the sample 383 also revealed an overlay of a cytosine and a thymine peak (data not shown). The results for sample 354 favor the notion that this was a false positive. This is because there were many different types of SNPs. In addition to the wild-type three different substitutions $(G \rightarrow T, C \rightarrow T$ und $C \rightarrow A)$ at three different positions were found in the plasmids produced from the same genomic sample 354 . Direct sequencing of a PCR product of the 3'-MON810 region of sample 354 showed wild-type. Although a plant cultivated from sample 354 would have provided useful information, this approach was not feasible because the whole maize kernel was homogenized for DNA extraction.

It is unknown whether the partially triploid state of the grain may have influenced the results. Endosperm, a triploid tissue, accounts for $80 \%-90 \%$ of the maize kernel's weight. Endosperm contains two maternal and one paternal genome copies. For interpreting the results, it is important to consider 
the degree of zygosity of the analyzed maize variety. It makes a difference if the seeds are hemior homozygous for the transgenic locus and in the case of hemizygosity, it is important to know if the transgene donor is male or female [43]. The degree of zygosity in the analyzed maize variety $($ MON88017 × MON810) remains unknown.

Table 11. Overview of the sequencing results for 3 '-MON810 plasmids. Plasmids sequenced because of the screening results are marked with *. All other plasmids were sequenced subsequently because of the prior sequencing results. The confidence values are shown together with sequencing results for a better overview.

\begin{tabular}{|c|c|c|c|}
\hline Plasmid & Confidence Value & SNP & Position \\
\hline $263-2$ & 67.69 & no & \\
\hline $263-3$ & 72.02 & no & \\
\hline $263-4$ & 66.57 & no & \\
\hline $263-5$ & 62.97 & no & \\
\hline $263-7$ & 82.78 & no & \\
\hline $263-8$ & 88.24 & no & \\
\hline $264-1$ & 88.51 & no & \\
\hline $264-2 *$ & 7.99 & $\mathrm{C} \rightarrow \mathrm{T}$ & 71 \\
\hline $264-3 *$ & 4.61 & $\mathrm{C} \rightarrow \mathrm{T}$ & 71 \\
\hline $264-4 *$ & 4.95 & $\mathrm{C} \rightarrow \mathrm{T}$ & 71 \\
\hline $264-6 *$ & 6.01 & $\mathrm{C} \rightarrow \mathrm{T}$ & 71 \\
\hline $264-7 *$ & 7.97 & $\mathrm{C} \rightarrow \mathrm{T}$ & 71 \\
\hline $264-9$ & not tested & $\mathrm{C} \rightarrow \mathrm{T}$ & 71 \\
\hline $345-2$ & 64.71 & no & \\
\hline $345-3$ & 75.71 & no & \\
\hline $345-4$ & 78.59 & no & \\
\hline $345-6$ & 91.02 & no & \\
\hline $352-1$ & 81.06 & no & \\
\hline $352-2$ & 96.06 & no & \\
\hline $354-1$ & 44.77 & $\mathrm{G} \rightarrow \mathrm{T}$ & 74 \\
\hline $354-2 *$ & 15.97 & $\mathrm{C} \rightarrow \mathrm{T}$ & 86 \\
\hline $354-3$ & 90.48 & no & \\
\hline $354-4$ & 64.39 & $\mathrm{C} \rightarrow \mathrm{A}$ & 84 \\
\hline $354-5$ & 62.92 & $\mathrm{C} \rightarrow \mathrm{A}$ & 84 \\
\hline $354-6$ & 81.43 & no & \\
\hline $355-3$ & 89.48 & no & \\
\hline $355-7$ & 94.76 & no & \\
\hline $374-2$ & 99.14 & no & \\
\hline $374-8$ & 96.73 & no & \\
\hline $383-1 *$ & 3.14 & $\mathrm{C} \rightarrow \mathrm{T}$ & 71 \\
\hline $383-2$ & 100.00 & no & \\
\hline $383-5$ & 97.56 & no & \\
\hline $383-7$ & 95.53 & no & \\
\hline $383-8 *$ & 6.40 & $\mathrm{C} \rightarrow \mathrm{T}$ & 71 \\
\hline $383-9 *$ & 2.94 & $\mathrm{C} \rightarrow \mathrm{T}$ & 71 \\
\hline $383-11$ & not tested & $\mathrm{C} \rightarrow \mathrm{T}$ & 71 \\
\hline
\end{tabular}


Figure 8. The sequencing chromatogram of the 3'-MON810 target region of sample 264 clearly showed a double peak at position 71 . Double peaks occur when different alleles are present.

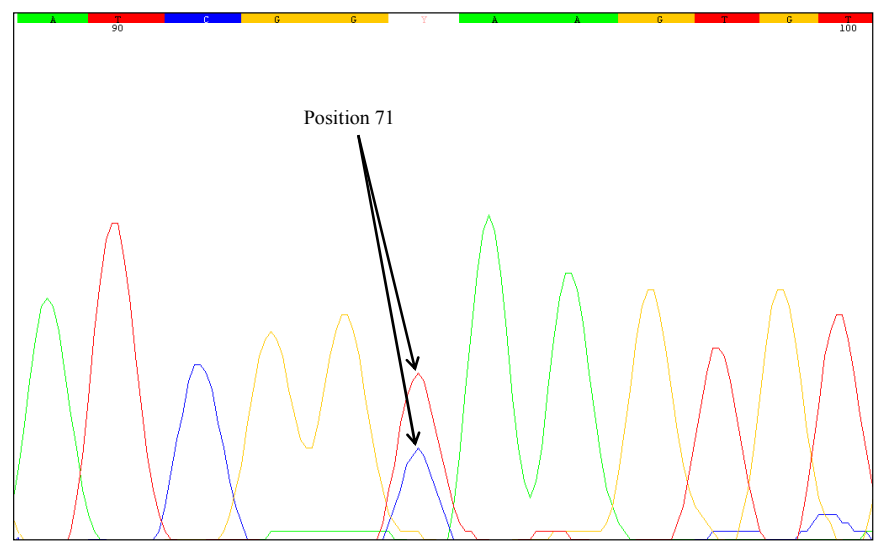

All SNPs detected in a study by Ogasawara et al. were silent mutations [44]. Silent mutations do not result in an altered amino acid sequence. The SNPs at position 71 identified in samples 264 and 383 were also silent mutations (the codons GGC and GGT both code for the amino acid glycine). This is illustrated in Figure 9. The detected SNP lies within the coding region of the crylAb toxin.

Figure 9. The analyzed 3'-MON810 target region is shown. The underlined DNA sequence belongs to the transgenic construct. The forward primer is shown in blue and the reverse primer in red. The SNP location is highlighted in yellow and the affected codon is framed blue. Cytosine is substituted by a thymine at position 71. The amino acid sequence of the cryl $\mathrm{Ab}$ gene is shown below the nucleotide sequence. The coded amino acid glycine (marked in yellow) is not affected by the SNP. The stop codon (framed red) lies within the genomic DNA because a truncation event at the $3^{\prime}$ end of the cryIAb gene led to the loss of the nopaline synthase (NOS) terminator (for more details see [17]).

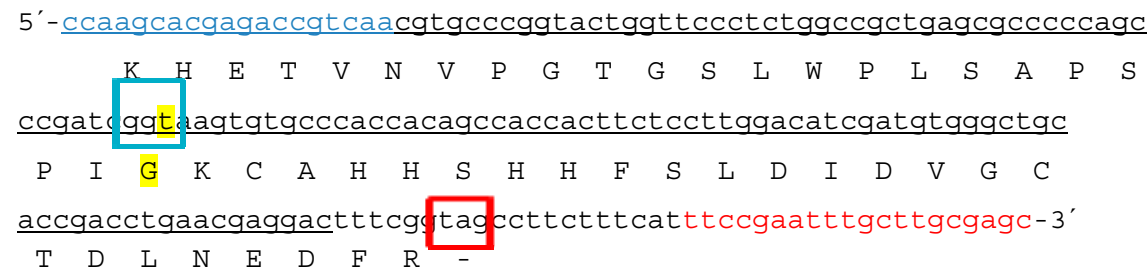

The results showed that a nucleotide change at the 3'-MON810 region was present in two out of 100 analyzed samples. However, the true rate of mutation at the $3^{\prime}$ end of the MON810 transgene in MON88017 $\times$ MON810 remains unknown. For an estimation of this rate, a higher number of samples need to be analyzed.

\section{Experimental Section}

Unless stated otherwise, the chemicals, PCR reagents, and PCR primers used were of analytical grade and were purchased from Biozym (Hessisch Oldendorf, Germany) (PCR reagents) and Sigma-Aldrich (Vienna, Austria) (PCR primers and chemicals). The Zero Blunt TOPO PCR Cloning kit (Invitrogen, Vienna, Austria), EasyPrep Pro Plasmid Miniprep kit (Biozym), JM109 Competent Cells (>107 cfu/ $\mu \mathrm{g}$, 
Promega, Mannheim, Germany), Wizard DNA Clean-up System (Promega), Phusion Hot Start II High-Fidelity DNA Polymerase kit (Biozym), and Type-it HRM PCR Kit (Qiagen, Hilden, Germany) were used according to the respective manufacturer's recommendations. The stacked event MON88017-3 × MON-00810-6 (hybrid 4421VT3) maize was obtained from Croplan Genetics ${ }^{\circledR}$ (Williston, ND, USA). And the GT73 (MON-00073-7) oilseed rape seeds were obtained by taking plants randomly from a field in Saskatchewan, Canada (season 2011). GT73 oilseed rape plants were cultivated in a closed system (in a separate room under controlled conditions: day/night $20 \pm 2{ }^{\circ} \mathrm{C}$, $12 / 12 \mathrm{~h} \mathrm{light/dark,} \mathrm{r.} \mathrm{h.} 60 \% \pm 5 \%$ ). Leaves were harvested after four weeks and immediately frozen in liquid nitrogen.

\subsection{Extraction of Genomic DNA}

Maize seeds were homogenized with a household garlic crusher. Plant leaves of GT73 were crushed using a mortar and a pestle after cooling with liquid nitrogen. A total $100 \mathrm{mg}$ of the homogenized leaves (GT73) or $150 \mathrm{mg}$ of the homogenized seeds (MON88017 $\times$ MON810) were incubated with a mixture of $820 \mu \mathrm{L}$ of TNE buffer (10 mM Tris (pH 8), $150 \mathrm{mM} \mathrm{NaCl,} 2 \mathrm{mM}$ EDTA (pH 8)), $1 \% \mathrm{SDS}, 150 \mu \mathrm{L}$ of $5 \mathrm{M}$ Guanidine- $\mathrm{HCl}$, and $30 \mu \mathrm{L}$ of proteinase $\mathrm{K}(600 \mu \mathrm{g} / \mathrm{mL})$ overnight at $60{ }^{\circ} \mathrm{C}$ under constant shaking. Following this, the mixture was centrifuged for $5 \mathrm{~min}$ at $16,100 \times \mathrm{g}$. To $600 \mu \mathrm{L}$ of the supernatant, $300 \mu \mathrm{L}$ of chloroform (99\%) was added and the mixture was vortexed for $20 \mathrm{~s}$. The mixture was then centrifuged at $16,100 \times g$ for 8 min to separate the phases and $500 \mu \mathrm{L}$ of the aqueous phase was transferred into a new tube. To this, $4 \mu \mathrm{L}$ of RNAse $(32 \mu \mathrm{g} / \mathrm{mL})$ was added, and the mixture was incubated at $60{ }^{\circ} \mathrm{C}$ for 30 min under constant shaking. The extracted DNA was purified using the Wizard DNA Clean-up System (Promega). After a pre-elution with $20 \mu \mathrm{L}$ of $\mathrm{ddH}_{2} \mathrm{O}$, the DNA was eluted with $10 \mathrm{mM}$ Tris buffer $\left(\mathrm{pH} \mathrm{7.4,70}{ }^{\circ} \mathrm{C}\right)$ for $10 \mathrm{~min}$. The eluted DNA was immediately stored at $-20^{\circ} \mathrm{C}$.

\subsection{Instruments Used for HRM and Scorpion Analysis}

Scorpion PCR experiments can be performed on any standard real-time PCR instrument. For HRM analysis, it is necessary to use a specific cycler optimized for precise melting analysis that uses dedicated heating algorithms and specific software [45,46]. For the Scorpion PCR as well as for the HRM experiments a Rotor-Gene Q (Qiagen) instrument was used. For the calculation of the scores (confidence values) of the HRM analysis, a specific software package (Rotor-Gene 2.0.2.4, Qiagen) of the Rotor-Gene Q cycler was used.

\subsection{Screening by Real-Time PCR Using Scorpion Primers and HRM Analysis}

A total 510 individual oilseed rape samples (GT73) and 100 individual maize samples (MON88017 $\times$ MON810) were analyzed on different days by three different operators. The mean of the values was calculated and was used for further investigation. Pools of genomic samples (for primary screenings) or plasmids (secondary screenings) served as reference to calculate the confidence values. The reference served as a control for the performance of all samples (including a positive (standard) 
control as well as a non-template control), allowed for the verification of the validity of all parameters of the run, and provided a reference value that enabled a comparison of different runs.

Unimolecular, singular Scorpion primers consisting of forward/reverse PCR-primer sequences as well as additional elements were used for this work. The additional elements included a PCR stopper to prevent the PCR read-through of the probe element, and a specific probe sequence with a fluorescence-based detection module consisting of a fluorophore and a quencher. The PCR yields an amplicon containing a sequence that is complementary to the Scorpion probe. The specific probe sequence then binds to its complementary sequence within the amplicon, the hairpin loop opens up, and a signal is produced [32,39].

With HRM analysis, the melting point $(T \mathrm{~m})$ of the amplicon produced is determined after the PCR reaction. This is achieved by gradually increasing the temperature from the annealing temperature up to $95{ }^{\circ} \mathrm{C}$. Simultaneously, the fluorescence of a DNA intercalating dye is measured. Because high-precision temperature control and fluorescence measurement are required for successfully implementing this method, such measurements can only be made using an HRM-certified equipment [40].

\subsection{Qualitative PCR for Cloning}

The PCR was performed with genomic DNA as template. A total $20 \mu \mathrm{L}$ of the reaction mixture contained $4 \mu \mathrm{L}$ of $5 \times$ Phusion HF-buffer (proprietary information, $1.5 \mathrm{mM} \mathrm{MgCl}_{2}$, error rate was $4.4 \times 10^{-7}$ ), $500 \mathrm{nM}$ of each primer, $250 \mu \mathrm{M}$ of each deoxynucleoside triphosphate (dNTP), 0.4 U Phusion Hot Start II DNA Polymerase, and $50 \mathrm{ng}$ of DNA. The temperature profile is shown in Table 12.

Table 12. The PCR temperature profile of the two-step protocol used for analysis. Touchdown PCR was used to eliminate non-specific amplification. Therefore, the annealing temperature started at $66^{\circ} \mathrm{C}$ and was lowered by $0.5{ }^{\circ} \mathrm{C}$ per cycle for the first 18 cycles. The last 22 cycles had an annealing temperature of $60^{\circ} \mathrm{C}$.

\begin{tabular}{cccc}
\hline Cycle Step & Temp. & Time & Number of Cycles \\
\hline Initial denaturation & $98^{\circ} \mathrm{C}$ & $2 \mathrm{~min}$ & \\
\hline Denaturation & $98^{\circ} \mathrm{C}$ & $10 \mathrm{~s}$ & \\
Annealing & $66-57.5^{\circ} \mathrm{C}$ Touchdown $\left(-0.5^{\circ} \mathrm{C}\right.$ each cycle $)$ & $30 \mathrm{~s}$ & 18 \\
Extension & $72{ }^{\circ} \mathrm{C}$ & $30 \mathrm{~s}$ & \\
\hline Denaturation & $98^{\circ} \mathrm{C}$ & $10 \mathrm{~s}$ & \\
Annealing & $60^{\circ} \mathrm{C}$ & $30 \mathrm{~s}$ & 22 \\
Extension & $72^{\circ} \mathrm{C}$ & $30 \mathrm{~s}$ & \\
\hline Final extension & $72^{\circ} \mathrm{C}$ & $7 \mathrm{~min}$ & \\
\hline
\end{tabular}

A $1 \mu \mathrm{L}$ aliquot of the PCR product was ligated and cloned into pCR-Blunt II-TOPO using the Zero Blunt TOPO PCR Cloning kit (Invitrogen) and transformed into JM109 Competent Cells. Colonies were grown in $5 \mathrm{~mL}$ of LB-medium and the recombinant DNA was isolated with the help of EasyPrep Pro Plasmid Miniprep kit (Biozym). Positive colonies were analyzed for the correct length of inserts using agarose gel electrophoresis on $2.5 \%$ gels. The validity of the insert was then verified by sequencing using M13 primers. 


\subsection{Real-Time PCR and HRM Conditions}

Real-time PCR was performed on a Rotor-Gene Q (Qiagen) instrument. The total volume of the reaction mixture was $16 \mu \mathrm{L}$. The Type-it HRM PCR Kit (Qiagen), $700 \mathrm{nM}$ primers (Scorpion primer $125 \mathrm{nM})$, and $1.6 \mu \mathrm{L}$ of undiluted DNA $(70-100 \mathrm{ng} / \mu \mathrm{L})$ template were used for each reaction. The thermal cycling profile used is shown in Table 13.

Table 13. The thermal cycling profile of the real-time PCR (prior to HRM analysis) experiment.

\begin{tabular}{cccc}
\hline Cycle Step & Temperature & Time & Number of Cycles \\
\hline Initial Denaturation & $95{ }^{\circ} \mathrm{C}$ & $5 \mathrm{~min}$ & \\
\hline Denaturation & $95{ }^{\circ} \mathrm{C}$ & $10 \mathrm{~s}$ & 55 \\
Annealing & $55^{\circ} \mathrm{C}$ & $30 \mathrm{~s}$ & \\
Extension & $72{ }^{\circ} \mathrm{C}$ & $20 \mathrm{~s}$ & \\
\hline
\end{tabular}

The experiments were performed on different days and the mean of the values was calculated and was used for further analysis. HRM was performed with the temperature increasing at a rate of $0.2{ }^{\circ} \mathrm{C}$ per $4 \mathrm{~s}$. The initial and final temperatures were 70 and $95{ }^{\circ} \mathrm{C}$, respectively. The melting curves and the temperature-shifted curves were normalized to enable the comparison of samples. Modified curves and HRM scores were obtained using the Rotor-Gene Q series software (version 2.0.2.4, Qiagen). The normalized and temperature-shifted melting curves corresponded to the final curve after normalization. When an amplicon harbored a sequence variation, the normalized and temperature-shifted melting curves had a different shape from those of the wild-type amplicons (see Supplementary Figures S3 and S4).

\subsection{Sequencing}

All sequence analyses were performed using the Sanger sequencing method. The BigDye Fast cycle sequencing protocol, described by Platt et al. [47], was used for this purpose. The M13 sequences necessary for sequencing were present in the plasmids generated, as the cloning vector contained these sequences. To avoid sequencing errors, both forward and reverse sequencing were included in the method. This insured the reliability of the sequencing results.

\subsection{Primers}

Primers used for this work are shown Table 1.

\section{Conclusions}

The objective of the present work was to identify DNA alterations that may cause genetic instability in GMOs, particularly in stacked events. The number of mutated samples we found in our study was two (out of 100 stacked maize samples tested). A much higher number of samples was analyzed ( $n=567$ MON810 maize samples and $n=1034$ RRS 40-3-2 samples of soy) in earlier studies that found no DNA alterations in soybean and maize [31,32]. The SNP frequency we observed in our study markedly exceeds the natural mutation rate. The average single-base substitution rate for maize is estimated to be $5.39 \times 10^{-8}$ per site per year and for genic maize regions, $4.79 \times 10^{-8}$ per site per 
year [48]. One important point to mention is that the detected SNPs were most likely not identified by low-sensitivity methods such as Southern Blot analysis.

Increased rate of mutation at the border regions may have a negative influence on GMO quantification by real-time PCR. Madi et al. [31] concluded that analysis of DNA instabilities in regions commonly used for the quantification of GMOs is particular important. Therefore, in canola and maize, the border regions from the genome into the construct at the $5^{\prime}$ and $3^{\prime}$ regions of the relevant transgene were tested in our study. Mutations were detected only in the 3'-MON810 region. Therefore, the 5'-MON810 region appears to be more suitable for GMO quantification as no instabilities were identified in this region. Based on the definition that the first base (at the $5^{\prime}$ end) of the analyzed 3'-MON810 target region is at position one, we found that both of the mutated samples harbored an SNP at position 71. However, by investigating a higher number of stacked maize samples $($ MON88017 $\times$ MON810), it cannot be excluded that SNPs would be identified at (other) positions which may change the transgenic protein. The inserted 3' flanking region of MON810 is a truncated version of MON810. The 3' end of the crylAb gene and the nopaline synthase (NOS) terminator were lost during the plant transformation [49]. It is also possible that the occurrence of the SNP detected in this study at the same region was random. One additional aim of this study was to evaluate the impact of the identified SNP on the amino acid sequence. Similar to that reported by Ogasawara et al. [44], the identified mutation was silent, meaning the amino acid sequence remained unchanged. Therefore, it is conceivable that the phenotype of the sample was not altered.

One unresolved question is the degree of zygosity of the transgene in the samples examined. Direct sequencing of the PCR products generated from the mutated samples indicated heterozygosity at nucleotide position 71. Two different nucleotides were identified at this position, a cytosine as wild-type and a thymine as mutant-type. The sequencing chromatograms of the PCR products clearly showed an overlay of these bases. However, sequencing errors could lead to similar chromatograms. Some positions may show overlapping nucleotides and it can be difficult to recognize heterozygous mutations just by direct sequencing of the PCR products. Therefore, we used the cloning approach described by Madi et al. [31]. Plasmids containing DNA of one allele can be obtained from genomic samples with heterozygous alleles. With clones comprised of one allele, the outcome of sequencing is unambiguous and sequencing error can be ruled out. PCR products of the affected samples were sequenced twice (forward and reverse). The plasmids of the MON88017 $\times$ MON810 samples 264 and 383 were also sequenced twice.

In Neumann et al. [32] and Madi et al. [31] the question was asked if the scores or the distribution of the values of the primary tests, (i.e., the $C_{\mathrm{t}}$ values of the Scorpion PCR and the confidence values of the HRM analyses) can be used to detect mutations. Our results show that the distribution of the values does not necessarily indicate the presence of mutations (Figures 2, 4, 6 and 7). For samples harboring mutations, two groups can be expected: samples with very high confidence values (wild-type) and those with very low confidence values (mutated samples). However, only Figure 4 (belongs to the distribution of 3'-GT73 samples) showed a distribution consistent with this description and no mutations were identified in these samples. In contrast, the distribution of the values of the $3^{\prime}-\mathrm{MON} 810$ screening did not show the expected characteristics. However, mutations were found in the 3 '-MON810 region. 
Based on the mutations identified by this work, we conclude that cloning is required for the unambiguous characterization of SNPs in GMOs. In addition to the two mutations, we also encountered false positive results revealed through subsequent investigation. The different plasmids of the affected sample (354 of MON88017 × MON810 maize) showed inconsistent SNPs (Table 11). Although PCR error is a possible explanation, the precise nature of the factors that contributed to the false positive result is not known. Additionally, plasmid 275-8 of the 5'-MON810 region showed an SNP, which was assessed as due to error in the cloning sequence. A related aspect is the number of plasmids required. Our results show that minimum six to 10 plasmids are necessary for the characterization of heterozygous samples.

Whereas earlier studies investigated single MON810 maize events [20,32], the present work focused on stacked maize event containing MON810. Stacked events having the same promoter are more susceptible to unintended effects of the transgenic event expression [50]. Many stacked events carry transgenes that use the same promoter. The 35S promoter, a viral element, occurs twice in MON88017 $\times$ MON810 maize. Kohli et al. discussed that the 35S promoter contains a recombination hot spot that has an influence on GMOs [51]. Since stacked events contain multiple viral promoters the susceptibility to instabilities may be increased. Due to an increasing number of stacked events being commercialized, there is a proportionally-relevant need for the analysis of their genetic stability in the context of the specific stacked event in question on a case-by-case basis. Due to the present results one might assume that stacked events tend to be more instable than single events. To confirm this assumption, it would be necessary to demonstrate further instabilities of MON810 in other stacked events. Corresponding experiments are planned. In these, it will be important to analyze whether stacking of the transgenes, and the means by which the stacked varieties were created, may be a contributing factor. It also will be necessary to understand the potential characterization (regulatory) and biosafety issues that may be relevant.

For future studies, it may also be interesting to analyze the zygosity degree of the mutated samples in detail.

\section{Supplementary Materials}

Supplementary materials can be found at http://www.mdpi.com/1422-0067/15/11/19898/s1.

\section{Acknowledgments}

We would like to express our gratitude to all three anonymous reviewers for their helpful and detailed comments. The staff costs for this work were partially supported by the Austrian Research Promotion Agency (FFG) through FEMtech internships for the students.

\section{Author Contributions}

Christian Brandes, Rupert Hochegger and Alexander G. Haslberger conceived and designed the experiments. Christian Brandes supervised the project. Sina-Elisabeth Ben Ali and Zita Erika Madi performed the experiments. Bernhard Prewein performed sequencing and provided technical advice. Christian Brandes, Zita Erika Madi and Sina-Elisabeth Ben Ali analyzed the data. Christian Brandes, 
Sina-Elisabeth Ben Ali and David Quist wrote the paper. David Quist provided material for the experiments.

\section{Conflicts of Interest}

The authors declare no conflict of interest.

\section{References}

1. James, C. Global Status of Commercialized Biotech/GM Crops; ISAAA Briefs: Cornell University, Ithaca, NY, USA, 2013; p. 46.

2. Taverniers, I.; Papazova, N.; Bertheau, Y.; de Loose, M.; Holst-Jensen, A. Gene stacking in transgenic plants: Towards compliance between definitions, terminology and detection within the EU regulatory framework. Environ. Biosaf. Res. 2008, 7, 197-218.

3. Hernandez, M.; Rodriguez-Lazaro, D.; Ferrando, A. Current methodology for detection, identification and quantification of genetically modified organisms. Curr. Anal. Chem. 2005, 1, 203-221.

4. Pla, M. Insert stability and transgenic plant risk. In Encyclopedia of Biotechnology in Agriculture and Food; CRC Press Inc.: London, UK, 2012.

5. Forsbach, A.; Schubert, D.; Lechtenberg, B.; Gils, M.; Schmidt, R. A comprehensive characterization of single-copy T-DNA insertions in the Arabidopsis thaliana genome. Plant Mol. Biol. 2003, 52, $161-176$.

6. Latham, J.R.; Wilson, A.K.; Steinbrecher, R.A. The Mutational consequences of plant transformation. J. Biomed. Biotechnol. 2006, 2006, 1-7.

7. Wilson, A.K.; Latham, J.R.; Steinbrecher, R.A. Transformation-induced mutations in transgenic plants: Analysis and biosafety implications. Biotechnol. Genet. Eng. Rev. 2006, 23, 209-237.

8. Smith, N.; Kilpatrick, J.B.; Whitelam, G.C. Superfluous transgene integration in plants. Crit. Rev. Plant. Sci. 2001, 20, 215-249.

9. Nacry, P.; Camilleri, C.; Courtial, B.; Caboche, M.; Bouchez, D. Major chromosomal rearrangements induced by T-DNA transformation in Arabidopsis. Genetics 1998, 149, 641-650.

10. Windels, P.; de Buck, S.; van Bockstaele, E.; de Loose, M.; Depicker, A. T-DNA integration in Arabidopsis chromosomes. Presence and origin of filler DNA sequences. Plant Physiol. 2003, 133, 2061-2068.

11. McCabe, M.S.; Mohapatra, U.B.; Debnath, S.C.; Power, J.B.; Davey, M.R. Integration, expression and inheritance of two linked T-DNA marker genes in transgenic lettuce. Mol. Breed. 1999, 5, 329-344.

12. Belgian Biosafety Server. Available online: http://www.biosafety.be/gmcropff/EN/TP/MGC.html (accessed on 14 July 2014).

13. Tizaoui, K.; Kchouk, M.E. Genetic approaches for studying transgene inheritance and genetic recombination in three successive generations of transformed tobacco. Genet. Mol. Biol. 2012, 35, 640-649.

14. Choffnes, D.S.; Philip, R.; Vodkin, L.O. A transgenic locus in soybean exhibits a high level of recombination. In Vitro Cell. Dev. Biol. 2001, 37, 756-762. 
15. Waminal, N.E.; Ryu, K.H.; Choi, S.-H.; Kim, H.H. Randomly detected genetically modified (GM) maize (Zea mays L.) near a transport route revealed a fragile $45 \mathrm{~S}$ rDNA phenotype. PLoS One 2013, 8, e74060.

16. Ulian, E.C.; Magill, J.M.; Magill, C.W.; Smith, R.H. DNA methylation and expression of NPT II in transgenic petunias and progeny. Theor. Appl. Genet. 1996, 92, 976-981.

17. Rosati, A.; Bogani, P.; Santarlasci, A.; Buiatti, M. Characterisation of 3 ' transgene insertion site and derived mRNAs in MON810 YieldGard ${ }^{\circledR}$ maize. Plant Mol. Biol. 2008, 67, 271-281.

18. Nguyen, H.T.; Jehle, J.A. Quantitative analysis of the seasonal and tissue-specific expression of Cry1Ab in transgenic maize Mon810. J. Plant Dis. Prot. 2007, 114, 82-87.

19. Heinemann, J.A.; Kurenbach, B.; Quist, D. Molecular profiling-A tool for addressing emerging gaps in the comparative risk assessment of GMOs. Environ. Int. 2011, 37, 1285-1293.

20. La Paz, J.L.; Pla, M.; Papazova, N.; Puigdomènech, P.; Vicient, C.M. Stability of the MON810 transgene in maize. Plant Mol. Biol. 2010, 74, 563-571.

21. Coll, A.; Nadal, A.; Collado, R.; Capellades, G.; Kubista, M.; Messeguer, J.; Pla, M. Natural variation explains most transcriptomic changes among maize plants of MON810 and comparable non-GM varieties subjected to two N-fertilization farming practices. Plant Mol. Biol. 2010, 73, 349-362.

22. Coll, A.; Nadal, A.; Palaudelmàs, M.; Messeguer, J.; Melé, E.; Puigdomènech, P.; Pla, M. Lack of repeatable differential expression patterns between MON810 and comparable commercial varieties of maize. Plant Mol. Biol. 2008, 68, 105-117.

23. Barros, E.; Lezar, S.; Anttonen, M.J.; van Dijk, J.P.; Röhlig, R.M.; Kok, E.J.; Engel, K.H. Comparison of two GM maize varieties with a near-isogenic non-GM variety using transcriptomics, proteomics and metabolomics. Plant Biotechnol. J. 2010, 8, 436-451.

24. La Paz, J.L.; Pla, M.; Centeno, E.; Vicient, C.M.; Puigdomènech, P. The use of massive sequencing to detect differences between immature embryos of MON810 and a comparable non-GM maize variety. PLoS One 2014, 9, 1-13.

25. Agapito-Tenfen, S.Z.; Guerra, M.P.; Wikmark, O.G.; Nodari, R.O. Comparative proteomic analysis of genetically modified maize grown under different agroecosystems conditions in Brazil. Proteome Sci. 2013, 11, 1-15.

26. Rang, A.; Linke, B.; Jansen, B. Detection of RNA variants transcribed from the transgene in Roundup Ready soybean. Eur. Food Res. Technol. 2005, 220, 438-443.

27. EFSA GMO Panel. Guidance document of the Scientific Panel on Genetically Modified Organisms for the risk assessment of genetically modified plants and derived food and feed. EFSA J. 2006, 99, 1-100.

28. European Parliament. Directive 2001/18/EC of the European Parliament and of the Council of 12 March 2001 on the deliberate release into the environment of genetically modified organisms and repealing Council Directive 90/220/EEC-Commission Declaration. Available online: http:/eurlex.europa.eu/legal-content/EN/TXT/?uri=CELEX:32001L0018 (accessed on 12 March 2001).

29. Moch, K. Epigenetische Effekte bei transgenen Pflanzen: Auswirkungen auf die Risikobewertung. BfN-Skripten 2006, 187, 1-80. 
30. Broothaerts, W.; Corbisier, P.; Schimmel, H.; Trapmann, S.; Vincent, S.; Emons, H. A single nucleotide polymorphism (SNP839) in the adh1 reference gene affects the quantitation of genetically modified maize (Zea mays L.). J. Agric. Food Chem. 2008, 56, 8825-8831.

31. Madi, Z.E.; Brandes, C.; Neumann, G.; Quist, D.; Ruppitsch, W.; Hochegger, R. Evaluation of Adh1 alleles and transgenic soybean seeds using Scorpion PCR and HRM analysis. Eur. Food Res. Technol. 2013, 237, 125-135.

32. Neumann, G.; Brandes, C.; Joachimsthaler, A.; Hochegger, R. Assessment of the genetic stability of GMOs with a detailed examination of MON810 using Scorpion probes. Eur. Food Res. Technol. 2011, 233, 19-30.

33. EFSA GMO Panel. Scientific Opinion on Guidance for risk assessment of food and feed from genetically modified plants. EFSA J. 2011, 9, 2150.

34. EFSA GMO Panel. Guidance Document of the Scientific Panel on Genetically Modified Organisms for the risk assessment of genetically modified plants containing stacked transformation events. EFSA J. 2007, 512, 1-5.

35. EFSA GMO Panel. Opinion of the Scientific Panel on Genetically Modified Organisms on a request from the Commission related to the notification (Reference $\mathrm{C} / \mathrm{GB} / 02 / \mathrm{M} 3 / 3$ ) for the placing on the market of glyphosate-tolerant and insect-resistant genetically modified maize NK603 × MON810, for import and processing, under Part C of Directive 2001/18/EC from Monsanto. EFSA J. 2005, 308, 1-22.

36. EFSA GMO Panel. Scientific Opinion on application EFSA-GMO-NL-2011-97 for the placing on the market of insect-resistant and herbicide-tolerant genetically modified cotton T304-40 for food and feed uses, import and processing under Regulation (EC) No 1829/2003 from Bayer CropScience AG. EFSA J. 2013, 11, 3251.

37. Aguilera, M.; Querci, M.; Balla, B.; Prospero, A.; Ermolli, M.; van den Eede, G. A qualitative approach for the assessment of the genetic stability of the MON810 trait in commercial seed maize varieties. Food Anal. Methods 2008, 1, 252-258.

38. ISAAA. Available online: http://www.isaaa.org/gmapprovaldatabase (accessed on 1 July 2014).

39. Thelwell, N.; Millington, S.; Solinas, A.; Booth, J.; Brown, T. Mode of action and application of Scorpion primers to mutataon detection. Nucleic Acids Res. 2000, 28, 3752-3761.

40. Druml, B.; Cichna-Markl, M. High resolution melting (HRM) analysis of DNA-Its role and potential in food analysis. Food Chem. 2014, 158, 245-254.

41. Montgomery, J.; Wittwer, C.T.; Palais, R.; Zhou, L. Simultaneous mutation scanning and genotyping by high-resolution DNA melting analysis. Nat. Protoc. 2007, 2, 59-66.

42. Foissac, X. Taq Polymerase Errors in PCR: Frequency and Management. COST School on bioinformatical analyses of phytoplasma sequences: Vilnius, Lithuania, 2011; Available online: http://costphytoplasma.ipwgnet.org/PDF\%20files/Bioinformatics\%20school/Foissac\%202\%20Ta q\%20errors-r.pdf (accessed on 1 July 2014).

43. Zhang, D.; Corlet, A.; Fouilloux, S. Impact of genetic structures on haploid genome-based quantification of genetically modified DNA: Theoretical considerations, experimental data in MON 810 maize kernels (Zea mays L.) and some practical applications. Transgenic Res. 2008, $17,393-402$. 
44. Ogasawara, T.; Chikagawa, Y.; Arakawa, F.; Nozaki, A.; Itoh, Y.; Sasaki, K.; Umetsu, H.; Watanabe, T.; Akiyama, H.; Maitani, T.; et al. Frequency of mutations of the transgene, which might result in the loss of the glyphosate-tolerant phenotype, was lowered in Roundup Ready ${ }^{\circledR}$ soybeans. J. Health Sci. 2005, 51, 197-201.

45. Bush, S.M.; Krysan, P.J. iTILLING: A personalized approach to the identification of induced mutations in Arabidopsis. Plant Physiol. 2010, 154, 25-35.

46. Type-it HRM PCR Handbook. Available online: http://www.qiagen.com/resources/ resourcedetail?id=a800ede3-2322-4341-a5c1-a9cbb6f630a3\&lang=en (accessed on 14 July 2014).

47. Platt, A.R.; Woodhall, R.W.; George, A.L., Jr. Improved DNA sequencing quality and efficiency using an optimized fast cycle sequencing protocol. BioTechniques 2007, 43, 58-62.

48. Jiao, Y.; Zhao, H.; Ren, L.; Song, W.; Zeng, B.; Guo, J.; Wang, B.; Liu, Z.; Chen, J.; Li, W.; et al. Genome-wide genetic changes during modern breeding of maize. Nat. Genet. 2012, 44, 812-815.

49. Hernandez, M.; Pla, M.; Esteve, T.; Prat, S.; Puigdomenech, P.; Ferrando, A. A specific real-time quantitative PCR detection system for event MON810 in maize YieldGard based on the 3'-transgene integration sequence. Transgenic Res. 2003, 12, 179-189.

50. Mumm, R.H. A look at product development with genetically modified crops: Examples from maize. J. Agric. Food Chem. 2013, 61, 8254-8259.

51. Kohli, A.; Griffiths, S.; Palacios, N.; Twyman, R.M.; Vain, P.; Laurie, D.A.; Christou, P. Molecular characterization of transforming plasmid rearrangements in transgenic rice reveals a recombination hotspot in the CaMV $35 \mathrm{~S}$ promoter and confirms the predominance of microhomology mediated recombination. Plant. J. 1999, 17, 591-601.

(C) 2014 by the authors; licensee MDPI. Basel. Switzerland. This article is an open access article distributed under the terms and conditions of the Creative Commons Attribution license (http://creativecommons.org/licenses/by/4.0/). 